\title{
A REINVENÇÃO DA SOCIOLOGIA DA MODERNIZAÇÃO: LUIZ COSTA PINTO E FLORESTAN FERNANDES (1950-1970)
}

\author{
THE REINVENTION OF THE SOCIOLOGY OF MODERNIZATION: LUIZ COSTA PINTO AND \\ FLORESTAN FERNANDES (1950-1970)
}

Antonio Brasil Jr. ${ }^{1}$

Resumo Neste artigo, procura-se divisar o potencial teórico inscrito nas contribuições de dois sociólogos brasileiros à sociologia do desenvolvimento dos anos 1950-1970: Luiz Costa Pinto e Florestan Fernandes. Para tal, observa-se, a partir de três eixos, o sentido inovador de suas formulações em contraste com a sociologia da modernização norte-americana, àquela altura hegemônica: (a) suas concepções da prática sociológica, bem como de suas especificidades num contexto periférico; (b) suas visões sobre a dinâmica da mudança social no Brasil, tal qual forjadas em suas pesquisas sobre as relações entre brancos e negros; (c) e em suas sínteses teóricas dos anos 1960-70.

Palavras-chave pensamento social; desenvolvimento; Luiz Costa Pinto; Florestan Fernandes.
Abstract This article attempts to discern the theoretical potential inscribed in the contributions of two Brazilian sociologists to the sociology of development between 1950 and 1970: Luiz Costa Pinto and Florestan Fernandes. To this end, the innovative direction of their formulations is analyzed in contrast to the American sociology of modernization, which by then had become hegemonic. Such analysis is done from three views: (a) their conceptions of the sociological practice and of its specificities in a peripheral context; (b) their views on the dynamics of social change in Brazil, as forged in their research on relations between blacks and whites, (c) their theoretical syntheses of the 1960s and 1970s.

Keywords social thought; development; Luiz Costa Pinto; Florestan Fernandes. 
Neste trabalho, discutiremos, em linhas breves, de que modo dois dos principais sociólogos brasileiros, Luiz Costa Pinto e Florestan Fernandes, lograram realizar consideráveis inovações teóricas em relação a uma das principais teorizações de seu tempo: a sociologia da modernização norte-americana. A sociologia da modernização, cumpre lembrar aqui, foi uma das mais persuasivas e difundidas hipóteses sobre a mudança social da história da sociologia, tendo como traço característico uma compreensão ordeira, linear e, no limite, a-histórica do processo de mudança: todas as sociedades, ainda que em ritmos diferentes, se encaminhariam de um tipo de sociedade tradicional para outro, de sociedade moderna, vistos como formas contrapostas de estrutura social (Franco, 1970; Bendix, 1996; Gilman, 2007; Brasil Jr., 2011).

Evidentemente, a 'reinvenção' da sociologia da modernização que discutiremos aqui com base em Costa Pinto e Fernandes não é exclusiva deles, e tampouco privilégio da sociologia brasileira - virtualmente, todo e qualquer sociólogo situado na periferia teve de repensar, em algum grau, as pressuposições da sociologia da modernização diante das especificidades do novo contexto social (Maia, 2009; Domingues, 2011). Quer dizer, diante do possível descompasso entre a 'linearidade' da mudança pressuposta pela vertente teórica da sociologia da modernização e as trajetórias históricas contingentes assumidas pelos diferentes contextos nacionais, produziram-se certos deslocamentos teóricos cuja criatividade nos interessa analisar. ${ }^{2}$ Esse é, a nosso ver, o caso de Costa Pinto e Fernandes, autores que ainda hoje possuem significação teórica e cujos principais argumentos reconstruiremos aqui.

A fim de organizar o nosso argumento, dividiremos o texto em três partes. Na primeira, procuramos situar como o próprio entendimento da prática sociológica de Costa Pinto e Fernandes já discrepava significativamente do 'positivismo sociológico' hegemônico na sociologia norte-americana de então - e, por extensão, na sociologia da modernização. Na segunda, assinalamos a importância do acúmulo intelectual de suas pesquisas empíricas e reflexões teóricas em torno da questão racial no Brasil na reinterpretação do padrão de mudança social, uma vez que a reiteração das desigualdades entre brancos e negros sinalizava uma dinâmica histórica sui generis. Na terceira, e última, analisamos com mais vagar as principais inovações teóricas de Costa Pinto e Fernandes vis-à-vis a sociologia da modernização norte-americana, com os construtos 'marginalidade estrutural' e 'capitalismo dependente'.

\section{Uma sociologia inovadora e crítica}

Ainda que Luiz Costa Pinto e Florestan Fernandes tenham sido, talvez, os dois principais protagonistas da renovação da sociologia brasileira enquanto 
disciplina 'científica' dotada de critérios rigorosos de conceituação e investigação empírica, bem como amparada na monografia como meio expressivo por excelência (ver Maio e Villas Bôas, 1999; Arruda, 2001), os seus entendimentos da prática sociológica extravazaram, em vários sentidos, a versão 'positivista' da disciplina que então se difundia mundialmente, sobretudo por meio da sociologia norte-americana. ${ }^{3}$ Embora, por um lado, ambos tivessem a preocupação de fazer dos centros sociológicos aos quais se ligavam no Rio de Janeiro e em São Paulo - penso, especificamente, no Centro Latino-Americano de Pesquisas em Ciências Sociais (CLAPCS) e o Instituto de Ciências Sociais (ICS) da Universidade do Brasil, no caso de Costa Pinto, e na Cátedra de Sociologia I da Universidade de São Paulo (USP), no caso de Fernandes - um lugar à altura das sociologias mais avançadas de seu tempo, isso não significou, por outro lado, uma absorção acrítica da matéria sociológica 'importada' e, tampouco, a minimização do potencial teórico criativo que podia ser obtido a partir da exploração da realidade social brasileira. Dito de outro modo, tanto Costa Pinto quanto Fernandes assentaram as bases de uma sociologia ao mesmo tempo inovadora e crítica.

Essa preocupação por parte de Costa Pinto remonta a um texto publicado ainda na década de 1940 na revista Sociologia - e acompanhado de um comentário crítico de Fernandes, ao qual não temos espaço para aludir aqui (ver Lima, 1999) -, intitulado “Sociologia e mudança social" (1947). Nesse artigo, o autor afirma que a 'crise' pela qual passava a sociologia a ele contemporânea se devia, em parte, ao "profundo compromisso ideológico" que existia "em toda a produção acadêmica norte-americana" com "a ordem social dominante" (Costa Pinto, 1947, p. 324) - posição forte para a qual Costa Pinto procura sustentação não só nas formulações de Karl Marx, mas também em autores norte-americanos contemporâneos críticos da chamada sociologia mainstream, como Charles Wright Mills e Robert Lynd. Costa Pinto entende que, a fim de sair de sua 'crise', a sociologia não poderia deixar de ser eminentemente uma ciência crítica do existente.

No entanto, é principalmente em seus textos programáticos a favor de uma 'sociologia do desenvolvimento', já na passagem dos anos 1950 para a década seguinte, que Costa Pinto acena mais fortemente com a perspectiva de uma 'sociologia crítica' - não à toa, repetiu em diversas ocasiões que havia uma relação constitutiva entre a 'sociologia do desenvolvimento' e o 'desenvolvimento da sociologia'. Para ele, uma perspectiva consistentemente 'objetiva' sobre a realidade, isto é, não compromissada com o status quo, não estaria associada à simples postura de adesão pessoal do sociólogo à 'neutralidade valorativa', mas a processos sociais mais amplos. Nesse sentido, nas sociedades 'avançadas' ou 'desenvolvidas', nas quais o valor social dominante para ele já não seria a mudança, mas a estabilidade social, a tarefa de crítica do status quo encontraria maiores dificuldades - daí os problemas, 
segundo o autor, da sociologia norte-americana, que teria descaracterizado “o sentido profundamente racional e criador do pensamento sociológico, gerando (...) um hermetismo acadêmico que nada tem de autenticamente científico" (Costa Pinto, 1962, p. 7, tradução nossa). 4 Já nas sociedades em processo de desenvolvimento, como os países latino-americanos, a eleição da 'mudança' como valor social dominante facilitava a "sincronização dos valores de uma ciência criadora com os valores da ordem social em transformação" (Costa Pinto, 1962, p. 2, tradução nossa). ${ }^{5}$ Esta visão permitiu a Costa Pinto afirmar, por exemplo, que a renovação da sociologia como um todo deveria passar pela produção intelectual dos países subdesenvolvidos, pois, em seus termos, "talvez aqui, nestas paragens, neste mundo novo em gestação, possa a sociologia encontrar as condições ótimas para germinar com o impulso de um verdadeiro renascimento" (Costa Pinto, 1962, p. 6, tradução nossa). ${ }^{6}$ Isso ocorreria porque, ao forçarem a sociologia a lidar com problemas inteiramente novos, desprovidos de casuística na chamada 'sociologia acadêmica' (Costa Pinto, 1963a, p. 121), os sociólogos situados nos países da periferia estariam “em posição mais vantajosa que a dos colegas que trabalham nas chamadas sociedades superdesenvolvidas, onde a estabilidade, muito mais que a mudança, apresenta-se como valor social supremo" (Costa Pinto, 1963a, p. 142, tradução nossa). ${ }^{7}$ Em suma, Costa Pinto defende que, pela complexidade intrínseca às sociedades em rápido processo de transformação, a sociologia no Brasil (e na América Latina) poderia, caso exitosa, renovar a própria sociologia 'em crise'.

Com menor contundência, mas não com menor vigor, Fernandes avançou uma posição semelhante a respeito do potencial teórico da sociologia feita no Brasil e nos demais países subdesenvolvidos. Em seu famoso prefácio à primeira edição, em 1963, de A sociologia numa era de revolução social - livro no qual, aliás, Fernandes procura repensar as tarefas e dilemas da sociologia num contexto de transformações sociais aceleradas -, o autor coloca o problema da seguinte maneira:

Através de escolhas judiciosas, o sociólogo brasileiro pode contribuir de forma original e criadora para o enriquecimento de ramos da teoria sociológica que não podem ser cultivados com a mesma facilidade por seus colegas dos "países desenvolvidos" do mesmo círculo civilizatório. As sociedades que se afastam do tipo "normal", inerente a determinada civilização, representam, em si mesmas, um problema teórico para a ciência. As explicações válidas para o tipo "normal" nem sempre se aplicam às suas objetivações em condições especiais (...). Desse ângulo, a posição do sociólogo brasileiro é quase privilegiada, pois poderá propor-se tarefas de grande significação teórica para a sociologia. Basta que procure interpretar os fenômenos observados tendo em vista o que as descobertas representarem no contexto da análise sociológica da sociedade de classes (Fernandes, 1976, p. 19-20). 
Mesmo que, posteriormente, Fernandes coloque essa mesma questão de outra maneira - ele passará a ver o Brasil como um caso típico de 'capitalismo dependente', e não mais como um caso que se afastaria do 'tipo normal' da 'sociedade de classes', o que veremos com mais vagar na última seção deste texto -, o ponto de vista do autor é claro. Caberia à sociologia nos países subdesenvolvidos muito mais que uma simples 'aplicação' de teorias importadas dos centros mais avançados da disciplina: ela poderia dar uma contribuição substantiva ao enriquecimento da teoria sociológica como um todo (Bastos, 2011).

Além disso, Fernandes é bastante enfático ao rechaçar a tese da 'neutralidade valorativa', posto que, para ele, a separação entre os papéis de 'cientista' e 'cidadão' é uma posição de fundo conformista, além de esterilizante para a própria sociologia. Conforme anunciou em sua comunicação durante o V Congresso Mundial de Sociologia, realizado em 1962 em Washington, o

envolvimento dos sociólogos nos assuntos práticos da coletividade aumenta as (...) possibilidades de conhecer, de modo ativo, mais íntimo e penetrante, as bases dinâmicas das relações humanas e das polarizações do comportamento coletivo (Fernandes, 1976, p. 130).

Nesse passo, em vez do isolamento - ou da 'neutralidade' -, a "comunicação com o grande público" apresenta "nítida significação construtiva para o cientista e para a ciência" (Fernandes, 1976, p. 130). De acordo com Fernandes, esse contato 'íntimo' do sociólogo com os dilemas de sua própria sociedade é importante para além da dimensão cognitiva, dado que permite igualmente fazer da sociologia uma 'força social' nas tentativas de reconstrução social empreendida pelo 'homem comum' (termo do próprio autor). Afinal, para ele, a sociologia, enquanto forma de consciência 'racional' dos processos sociais, deve estar entrosada simultaneamente com os esforços coletivos de diferenciação e expansão da 'sociedade de classes', por um lado, e de democratização da sociedade, por outro - ambos são necessários, em sua perspectiva, para a completa penetração do elemento 'racional' na organização da vida social, cujo ponto de fuga está na universalização de uma 'ordem social competitiva'. Noutras palavras, a sociologia, a fim de conseguir real eficácia como 'força social', deve ser permanentemente crítica das desigualdades sociais vigentes.

Vimos, portanto, que, de diferentes modos, tanto Luiz Costa Pinto quanto Florestan Fernandes foram muito além de uma simples absorção de formas 'importadas' de entendimento da disciplina. Por um lado, acreditavam que a situação de 'subdesenvolvimento', pelas condições específicas que ele impõe à reflexão, pode representar uma oportunidade para a realização de 
inovações teóricas; por outro, na contramão do mainstream sociológico vigente, viam que a sociologia não podia deixar de ser crítica do status quo, sob pena de esterilização intelectual. Grosso modo, ambos colocaram em grande tensão o 'positivismo sociológico' que então se difundia, principalmente por meio da sociologia norte-americana.

\section{Pesquisas empíricas sobre o negro e crítica ao 'desenvolvimentismo'}

Afirmar que Costa Pinto e Fernandes apresentam um olhar crítico quanto à faceta mais visível da principal sociologia de seu tempo - a sociologia norte-americana - não significa dizer, porém, que ambos não tenham recorrido ao repertório teórico e metodológico da mesma quando da realização de suas pesquisas empíricas. Por exemplo, em suas investigações vinculadas ao projeto mais amplo da Organização das Nações Unidas para a Educação, a Ciência e a Cultura (Unesco) acerca das relações raciais no país (Maio, 1997), os dois autores fizeram amplo uso de técnicas de observação participante e em massa, e de mensuração de atitudes e valores, bem como das análises de distribuição ecológica de grupos sociais e das escalas de distância social, dentre outras, que então se difundiam mundialmente, sobretudo mediante os trabalhos da escola de Chicago, por um lado, e da Universidade de Columbia, por outro. Não por acaso, os dois autores polemizaram em reiteradas e diferentes ocasiões com as posições de Alberto Guerreiro Ramos, que via em grande parte dessas importações intelectuais uma simples forma de 'sociologia enlatada'. Se é verdade que, conforme defendemos aqui, Costa Pinto e Fernandes tensionaram em sentido crítico a sociologia dominante de seu tempo, os dois jamais deixaram de entender a sociologia como uma disciplina estritamente 'científica' e dotada de conceitos que aspiram à generalização, tampouco rejeitaram o legado intelectual dos clássicos da sociologia europeia e de parte da sociologia norte-americana.

Simultaneamente, podemos ver em suas pesquisas sobre o negro a emergência de uma visão sobre o padrão de mudança social da sociedade brasileira que lhes permitiu, cada um a seu modo, problematizar várias das hipóteses e perspectivas que então circulavam na sociologia, seja no debate interno ou externo. Por um lado, Costa Pinto e Fernandes questionaram o mito da 'democracia racial', tendo em vista o padrão radicalmente assimétrico de estratificação social no que tange às relações entre brancos e negros - contrariando, nesse ponto, além de interlocutores locais, as próprias expectativas da Unesco, agência financiadora do projeto. Por outro, também assinalaram o sentido limitado, precário e incerto da integração da população negra à sociedade moderna em expansão na metade do século XX, posto que a sua maioria mal havia ultrapassado o limiar do proletarização. 
Nesse sentido, ao lado de outras reflexões teóricas e iniciativas de pesquisa, podemos localizar nos textos de Costa Pinto e de Fernandes sobre a questão racial no Brasil um conjunto de problemas e reflexões que colocou em tensão o pressuposto, então compartilhado tanto pela sociologia da modernização norte-americana quanto pelos 'desenvolvimentistas' brasileiros, de que o processo de desenvolvimento econômico acelerado estaria associado à concomitante democratização da sociedade e da esfera política. Vejamos então, rapidamente, alguns dos principais argumentos de Costa Pinto e de Fernandes presentes, respectivamente, em O negro no Rio de Janeiro: relações de raças numa sociedade em mudança, publicado em 1953, e $A$ integração do negro na sociedade de classes, de 1965.8

Nessas duas pesquisas, dedicadas à situação do negro nas duas maiores cidades brasileiras, interessava aos autores ver em que medida as transformações estruturais por que passavam o Rio de Janeiro e São Paulo - notadamente os processos de urbanização e industrialização - estavam transformando os padrões tradicionais de relação racial. Para tal, tanto Costa Pinto quanto Fernandes, ainda que com variações, adotaram um procedimento relativamente parecido: com base numa exploração das condições estruturais em mudança (seja do ponto de vista demográfico, econômico ou de distribuição ecológica das populações negras), analisaram a persistência - tensionada - de formas de conduta e mentalidade típicas de uma ordem 'senhorial' no seio da nova ordem em expansão, até chegarem à análise sociológica das possibilidades e dos limites abertos com o associativismo negro no que toca ao combate das desigualdades entre brancos e negros. Digo com variações porque, além de diferenças na própria composição textual das duas pesquisas, ${ }^{9}$ Fernandes na fatura do argumento explorou muito mais a dimensão histórica e os dados qualitativos (especialmente histórias de vida e depoimentos orais) que Costa Pinto, além de ser bem diversa a relação de cada um com os intelectuais do meio negro. 10

Mesmo que não tenha feito propriamente uma análise histórica da situação do negro no Rio de Janeiro - Fernandes, especialmente no relatório inicial, apresenta uma extensa seção destinada ao material histórico referido ao papel do negro em São Paulo (Fernandes e Bastide, 2008, p. 27-90) -, Costa Pinto, assim como o seu colega paulista, assinala o horizonte limitado que a Abolição e o fim da monarquia descortinaram para a população negra (Costa Pinto, 1998, p. 274-275). Utilizando os dados do censo de 1940, os resultados para o Rio de Janeiro, encontrados por Costa Pinto - a despeito da grande concentração de população negra no antigo Distrito Federal -, apontavam para um quadro de grande desigualdade. Nos termos do autor:

(...) são sempre elevadas, em todos os grupos étnicos, as quotas de empregados; entre os pardos e pretos, porém, essas quotas são em regra mais altas do que entre 
os brancos. Comparando-se, dentro de cada grupo étnico, as posições de classe, constata-se a mínima representação dos de cor entre os empregadores e a forte concentração deles na posição de empregados. (...) mesmo na condição de empregado, varia o contingente de cor com a variação do status do ramo de atividade: entre os industriários 49,72\% dos empregados são de cor, enquanto que entre os bancários essa quota é de 7,20\% (Costa Pinto, 1998, p. 112-113).

Diante desse quadro, Costa Pinto é enfático, afirmando que, mesmo com a passagem para uma sociedade urbano-industrial, “a maior distância percorrida pela grande massa dos homens e mulheres de cor do Distrito Federal nos últimos setenta anos de mobilidade social" teria sido a "de escravo a proletário" (Costa Pinto, 1998, p. 144; grifado no original). Essa situação não seria diversa em São Paulo, embora agravada pela maior intensidade que ali assumiu a competição com o imigrante europeu pelos novos postos de trabalho que iam surgindo com o avanço do capitalismo (Fernandes, 2008a, p. 43-44). Após apresentar uma série de elementos explicativos para a situação de extrema penúria da população negra na capital paulistana - que vão desde a herança negativa da escravidão no processo de ressocialização para uma 'ordem competitiva', passam pelos efeitos sociopáticos e anômicos da pauperização e do isolamento sociocultural, até chegarem à análise dos problemas típicos de integração da 'família negra' (Fernandes, 2008a, p. 119-298) -, Fernandes traça a situação do negro na década de 1950 do seguinte modo:

(...) a diferença decisiva, que se estabelece em relação ao passado recente, diz respeito à aquisição de uma fonte estável de ganho. Em outras palavras, o negro e o mulato conquistaram "meios de vida" que lhes proporcionam posições regulares (e por vezes permanentes) no seio do sistema de trabalho livre. No entanto, essas posições nem sempre asseguram classificação no sistema capitalista de relações de produção. Por isso, associam-se, variavelmente, com ocupações que proporcionam baixos níveis de remuneração e condicionam formas mais precárias da participação da estrutura de poder da sociedade inclusiva. Sob esses aspectos, há uma diferença considerável com referência ao passado (...). Mas essa diferença é meramente de grau. A "população de cor" ainda está confusamente empenhada na luta por converter o trabalho livre em fonte de classificação socioeconômica e de mobilidade social vertical (Fernandes, 2008b, p. 158-159).

Em suma, os dois autores chamam atenção em suas pesquisas para o fato de, em termos gerais, o processo histórico de modernização da sociedade brasileira antes repor do que superar as desigualdades entre brancos e negros legadas pela ordem escravocrata. Esse processo histórico excludente, continuam os autores, terminaria por refuncionalizar e dotar de novos sentidos 
a circulação de estereótipos e preconceitos em relação à suposta inferioridade 'racial' da população negra numa ordem social 'moderna' (Costa Pinto, 1998, p. 187; Fernandes, 2008b, p. 74) - o que, segundo o argumento inovador de Costa Pinto, sinalizava inclusive para um possível agravamento (e não uma diluição) das tensões raciais num cenário futuro de maior competição entre brancos e negros (Costa Pinto, 1998, p. 295). Nessa direção, ambos os autores mostram que a 'ideologia racial tradicional' (termo de Costa Pinto), ou uma 'visão estamental de mundo' (expressão de Fernandes), na qual brancos e negros são vistos numa ordenação hierárquica, poderia fazer-se presente mesmo numa sociedade de classes, supostamente avessa a formas extraeconômicas de estratificação, denunciando, assim, inconsistências, assincronias e desequilíbrios de fundo no padrão de mudança social no Brasil.

No entanto, em que pese o quadro de persistência de uma desigualdade racial secular - com toda a sorte de arcaísmos que ele traria consigo -, os dois autores não minimizaram as transformações na situação do negro no Rio de Janeiro e em São Paulo, especialmente a formação de uma pequena classe média negra e do associativismo a que ela deu suporte. Mesmo a partir de perspectivas bem diferentes, os dois autores se mostraram bastante céticos a respeito do potencial democratizante desses movimentos associativos, no sentido da reversão da desigualdade estrutural entre brancos e negros. Costa Pinto, aliás, se posicionou de maneira aguda e crítica em relação ao principal movimento negro da antiga capital do país, o Teatro Experimental do Negro (TEN) - que contava em suas fileiras, dentre outros, com Abdias Nascimento e Alberto Guerreiro Ramos. Entendendo a ideologia da 'negritude' gestada por esse movimento como resultado de um "horizonte de extrato médio, duplamente asfixiado por sua condição de raça e de classe" (Costa Pinto, 1998, p. 245), o autor assinala que o principal objetivo do movimento seria "adestrar o negro nos estilos das camadas dirigentes predominantemente brancas e socialmente dirigentes da sociedade brasileira" (Costa Pinto, 1998, p. 249). Nesse sentido, ele situa uma das principais 'terapêuticas' do TEN, o 'desrecalcamento em massa' da população negra, como forma inócua de combate às desigualdades estruturais de fundo, referindo-se a ela de modo bastante irônico:

[Esta prática] significa (...) que a angústia psicológica da cor e as limitações ideológicas de classe juntaram-se aqui para preparar o terreno no qual florescia a utópica aspiração de sair pelos morros, pelas favelas e pelos subúrbios levando a mensagem redentora da catarsis, o segredo da purgação dos recalques de tudo o que a fome, e o salário de fome, o baixo padrão de vida, a herança da escravidão, a "casa de cachorro", o analfabetismo, a doença, o preconceito e a linha de cor puseram na alma do homem do povo desta cidade, deste País e deste mundo (Costa Pinto, 1998, p. 254; grifos do autor). 
Fernandes não discordará dessa avaliação geral, posto que, para ele, a maioria dos movimentos no meio negro não levaria as suas ações para além dos limites da ordem social existente. Em seus termos, esses movimentos "restringiam o alcance inconformista" de suas ações, "impedindo que eles ultrapassassem as fronteiras do combate estrito aos resíduos do 'antigo regime' na ordenação das relações raciais" (Fernandes, 2008b, p. 43). No entanto, Fernandes jamais deixou de reconhecer os efeitos construtivos dos mesmos no processo de ressocialização da população negra de São Paulo nos valores e estilos de vida próprios a uma 'civilização urbana'. Só para ficarmos em um exemplo, o autor mostra como a circulação da noção de 'preconceito de cor', por meio dos periódicos produzidos por essas associações, teria elevado o grau de reflexividade do ajustamento social da população negra à ordem vigente (Fernandes, 2008b, p. 44). E, mais ainda, em que pese o acanhamento na crítica mais geral da ordem social, Fernandes é taxativo ao afirmar que as associações do meio negro foram as que levaram mais longe a defesa de um 'estilo democrático de vida':

Em suma, o negro e o mulato surgiam como os campeões da "revolução dentro da ordem". Exigiam a concretização e a plena vigência dos princípios e dos valores em que se fundava, legalmente, o equilíbrio da ordem social estabelecida. Por essa razão, eles se converteram em agentes históricos e evidenciam como as camadas populares, mantidas à margem do processo político na sociedade estamental e de castas, emergem nas pugnas ligadas à instauração e à consolidação do estilo democrático de vida (Fernandes, 2008b, p. 12).

Mesmo com essas discordâncias de avaliação sobre o significado sociológico do movimento negro no Rio de Janeiro e em São Paulo, podemos dizer que tanto Costa Pinto quanto Fernandes convergiram num ponto: as extremas dificuldades impostas (ou autoimpostas) à ação coletiva no meio negro no sentido da reversão das desigualdades raciais seculares. Daí o tom cético, mais forte em Costa Pinto que em Fernandes (pelo menos nesse período), no que se refere às expectativas mais amplas de transformação estrutural da sociedade brasileira, a despeito da velocidade das mudanças em curso. Assim, podemos ver que essas pesquisas empíricas, ao lado de outras investigações e reflexões teóricas, foram decisivas para a compreensão sociológica de um processo de modernização que parecia antes conciliar passado e presente que superar o primeiro em prol do último. Aliás, ambos são bastante claros neste sentido. Em O negro no Rio de Janeiro, assinala Costa Pinto:

O surgimento e a expansão de uma economia industrial moderna e o desenvolvimento (...) de uma civilização urbana no Brasil são fenômenos que significaram o início de uma série de contradições estruturais e profundas no interior de uma 
sociedade que começava a mudar as suas bases sem mudar, no mesmo ritmo, as formas sociais que sobre esta base repousavam. Nesta série de cultural lags sucessivos e acumulados, incluem-se as contradições, hoje visíveis, entre a ideologia racial tradicional e a nova situação racial, entre as quais uma distância crescente se cava, na medida em que a primeira resiste em se transformar e a segunda rapidamente se transforma (Costa Pinto, 1998, p. 61).

E Fernandes também chama atenção para o mesmo processo:

Quanto à sociedade inclusiva, a maior parte dos influxos negativos provinha da falta de sincronização entre a ordem social e a ordem racial. Os processos de mudança social, que operavam na diferenciação e na integração da estrutura social global, quase não repercutiam no padrão de ordenação societária das relações raciais. Por isso, enquanto a ordem social se alterava rapidamente, a ordem racial se convertia numa esfera em que prevalecia a demora sociocultural (Fernandes, 2008b, p. 74).

Mudanças descompassadas, passado e presente convivendo lado a lado, debilidades na superação de desigualdades e arcaísmos seculares - dimensões da sociedade brasileira que, tal qual traçadas nas pesquisas dos autores, faziam girar no vazio tanto as expectativas da sociologia da modernização norte-americana em relação ao padrão linear de mudança social quanto as crenças 'desenvolvimentistas' de que a sociedade brasileira replicaria, à sua maneira, um padrão 'clássico' de revolução burguesa democrática. Uma outra forma de entendimento do processo de mudança social era necessária a fim de se captarem as especificidades do desenvolvimento da sociedade brasileira (ou, em chave alargada, da América Latina). Cada um a seu modo, Costa Pinto e Fernandes elaboraram construtos teóricos inovadores de uma 'sociologia do desenvolvimento' que era, ao mesmo tempo, uma sociologia crítica do 'desenvolvimentismo', isto é, crítica dos anseios, generalizados no debate político da época, de que a modernização acelerada desaguaria necessariamente em um padrão de integração social democrático. É o que veremos, de forma breve, a seguir.

\section{‘Marginalidade estrutural' e 'capitalismo dependente' (inovações teóricas)}

A principal inovação teórica de Luiz Costa Pinto, no que se refere ao debate sociológico do desenvolvimento, é o construto 'marginalidade estrutural' - que, não por acaso, tem recebido a atenção de grande parte de seus intérpretes (Domingues, 1999; Liedke Filho, 1999; Villas Bôas, 1999). Embora, como o próprio autor destaca, essa formulação já tivesse sido esboçada por ele desde 
1947,11 é sobretudo em fins da década de 1950 que ela ganha maior densidade como perspectiva crítica das visões dualistas e lineares da mudança social. Muito grosso modo, através da noção de 'marginalidade estrutural' o autor procurou mostrar que, nas sociedades em desenvolvimento, não seriam apenas os elementos 'tradicionais' que estariam em crise por conta das mudanças sociais em curso, mas também o próprio padrão 'moderno' que se queria impor, porquanto incapaz de redesenhar a totalidade da estrutura social. Vejamos como ele justifica o emprego dessa noção numa nota de rodapé do artigo “Desenvolvimento: seus processos e obstáculos", de 1962, republicado logo depois em Sociologia e desenvolvimento (1963b):

Quando em 1947 propusemos o conceito de marginalidade estrutural para explicar os problemas de transição da sociedade brasileira (...) queríamos, em primeiro lugar, nos referir ao fato da estrutura social apresentar característicos de dois padrões - o arcaico e o novo, o tradicional e o moderno -, e, em segundo lugar, ao fato desses dois padrões, e não somente o arcaico, estarem ambos em crise. A nossa hipótese visava expressamente ampliar e completar o conceito já exposto por Boeke (...) e Furnivall (...), que cunharam a expressão "sociedade dual" ou "dualista" para indicar a mesma situação transitória, deixando, entretanto, a impressão de que o padrão arcaico está em crise e no novo padrão estariam todas as soluções. A dualidade consistiria, então, na coexistência de dois padrões como que hierarquizados numa escala de arcaísmo e progresso; enquanto o nosso conceito de marginalidade estrutural procura capitalizar a noção básica que se refere à presença de dois padrões - acentuando, entretanto, o fato de ambos estarem em crise. Isto, que pode parecer pura nuança, tem implicações metodológicas e práticas extremamente importantes (...) (Costa Pinto, 1963b, p. 96, grifos do autor).

Como alerta o próprio Costa Pinto, a introdução do termo 'marginalidade estrutural' está longe de ser uma simples nuança terminológica: ele chama atenção, contra as visões mais lineares, para o fato de que o padrão 'moderno', nas situações de transição rápida, não se generaliza para o conjunto do tecido social, coexistindo e se recompondo em muitos âmbitos -e de maneira muitas vezes ambígua - com o padrão 'tradicional'. Dito de outro modo, como nem os traços 'tradicionais' nem as características 'modernas' conseguem impor os seus dinamismos de maneira mutuamente exclusiva, o próprio sentido geral da mudança social seria aberto e contingente. Num dos muitos exemplos dados por Costa Pinto, vale a pena destacar a questão do sistema político. De acordo com o mainstream da 'sociologia da modernização', haveria uma correlação funcional forte entre desenvolvimento e democratização (Lipset, 1963). À luz da perspectiva da 'marginalidade estrutural', as repercussões do desenvolvimento na esfera política poderiam ser múltiplas e nem sempre democráticas: 
Nessas sociedades, por serem sociedades em transição, nas quais se encontram e coexistem situações objetivas as mais distintas e contraditórias, a impressão que se tem é que igualmente as mais diversas soluções políticas têm probabilidades equivalentes de prevalecer, desde a supercentralização política, desejada pelo "partido da ordem", até a "democracia popular", preconizada pela extrema revolucionária (Costa Pinto, 1963b, p. 99).

Por fim, e associada à noção de 'marginalidade estrutural', Costa Pinto introduz mais duas distinções finas que completam, a nosso ver, o quadro de inovações teóricas de sua 'sociologia do desenvolvimento'. Por um lado, a distinção entre os termos 'over-developed society' e 'well-developed society', que, esclarece o autor, "na bibliografia de língua inglesa" aparecem "sempre como sinônimos, propagando, consciente ou inconscientemente, uma tábua de valores e um critério de aferição ética, ideológica e política" (Costa Pinto e Bazzanella, 1967, p. 13).12 A proposta de nomear os países 'desenvolvidos' como 'superdesenvolvidos' implica toda uma rotação intelectual, porquanto permite questionar a adesão acrítica ao modelo societário por eles representados - e aí Costa Pinto inclui os países tanto do bloco capitalista quanto do bloco soviético. Um processo intenso de desenvolvimento não seria sinônimo necessariamente de 'bom' desenvolvimento - exemplo disso seriam os 'desequilíbrios e as assimetrias internas' presentes nos Estados Unidos e na União Soviética, o que comprovaria a coexistência, nesses países, de "muito desenvolvimento e desenvolvimento deformado" (Costa Pinto e Bazzanella, 1967, p. 13; grifado no original).

Por outro lado, ele introduz uma distinção entre 'modernização' e 'desenvolvimento', outros dois termos que também costumavam - e ainda costumam - andar juntos. De acordo com Costa Pinto, entre os dois processos representados por esses termos podem até existir correlações, "mas não identidade". E agrega: “ousamos, mesmo, adiantar que entre eles existe talvez uma oposição antitética e se explorarmos a análise destas diferenças poderemos aprender muito em relação ao processo de mudança social" (Costa Pinto, 1967, p. 193). Mas, afinal, em que se distinguem? Vale a pena transcrever um trecho do artigo "Modernização e desenvolvimento", originalmente uma conferência realizada em 1963 na Universidade de Buenos Aires:

(...) entendemos que modernização é um processo que consiste na adoção, por uma sociedade em mudança, de padrões de consumo, de comportamento, de instituições, valores e ideias característicos de sociedades mais avançadas enquanto desenvolvimento, por outro, implica mudanças estruturais que alteram basicamente o perfil da estrutura econômica e social. Nesse sentido a modernização, sociologicamente encarada, é um processo mais epidérmico, enquanto o desenvolvimento é um processo mais profundo. A modernização pode ser, por um tempo relativamente 
largo, compatível com a permanência de uma estrutura econômica e social de tipo colonial; enquanto o desenvolvimento, por definição, implica necessariamente o câmbio desta estrutura colonial de economia e de sociedade (Costa Pinto, 1967, p. 196).

Com base nessa definição, torna-se possível avaliar sociologicamente a 'qualidade' da mudança social progressiva. Isso porque Costa Pinto não desconsidera a 'modernização' como uma forma de mudança. “O que acontece", pondera, “é que, por definição, essas mudanças por largo tempo permanecem restritas a uma parte da sociedade" (Costa Pinto, 1967, p. 196). Justamente por esse aspecto 'restrito' e 'epidérmico', por terem gastado "tudo o que ganharam no passado modernizando a sua fachada e deixando intactas as bases estruturais de sua economia e de sua sociedade" (Costa Pinto, 1967, p. 189-199), as sociedades historicamente marcadas pela 'modernização' - como seria o caso do Brasil e da América Latina - chegariam a situações potencialmente (e politicamente) explosivas: "na medida em que o processo avança, o setor moderno vai exercendo uma espécie de 'efeito-demonstração' sobre as massas do setor arcaico, multiplicando necessidades e aspirações que o sistema não pode satisfazer sem se transformar" (Costa Pinto, 1967, p. 196). Portanto, apesar de promover a aceleração da dinâmica histórica, a 'modernização', por não romper com as condições estruturais de uma sociedade de tipo colonial, tenderia quase inevitavelmente a desembocar em 'crise': "a contradição se estabelece, as tensões se formam, as situações de conflito se generalizam, cria-se uma situação de instabilidade e de crise estrutural" (Costa Pinto, 1967, p. 196-197). Em suma, Costa Pinto traça o perfil de um padrão de mudança social que, além de repor reiteradamente arcaísmos de todo o tipo, está associado, de maneira crônica, a situações de enorme instabilidade social e política.

A produção teórica de Fernandes sobre o desenvolvimento levou mais tempo para atingir sua plena maturação - em outro trabalho (Brasil Jr., 2011), localizei no construto 'capitalismo dependente', que ganhou primeira definição explícita em 1967, o 'ponto de chegada' de Fernandes em seu processo de reinvenção da sociologia da modernização. Se é verdade, como vimos na sua produção sobre o negro em São Paulo, que o autor já se mostrava em alguma medida cético quanto às possibilidades da conexão entre desenvolvimento e democratização no início da década de 1960, é apenas com o construto 'capitalismo dependente' que Fernandes consegue dar conta do caráter estrutural do subdesenvolvimento e da orientação autocrática da sociedade brasileira.

Enquanto o construto 'marginalidade estrutural', mesmo que fruto direto das reflexões de Costa Pinto sobre a natureza da mudança social no Brasil, apresenta enorme generalidade, sendo aplicável às situações as mais 
diversas - Costa Pinto mobilizou-o igualmente para o caso latino-americano e para o mundo subdesenvolvido como um todo -, o construto 'capitalismo dependente', por sua vez, está sempre fortemente impregnado de matéria social e histórica específica, porquanto a forma de apresentação do mesmo por Fernandes depende igualmente da interpretação de momentos-chave da formação da sociedade brasileira. Isto não significa dizer que o autor não se tenha proposto a fazer generalizações teóricas - afinal, segundo o próprio Fernandes, o 'capitalismo dependente' seria típico de todos os países subdesenvolvidos da periferia capitalista, e não só referido ao Brasil. No entanto, a sua maneira de proceder à generalização implica o uso intensivo de contingências históricas específicas à sociedade brasileira, uma vez que esta sociedade seria um 'tipo extremo' da sociedade de classes conformada pelo 'capitalismo dependente' - nela, nos termos do autor, a "dependência é mais profunda e diferenciada e o subdesenvolvimento é mais desenvolvido" (Fernandes, 1981, p. 115). Quer dizer, a partir da sociedade brasileira, de sua dinâmica e impasses específicos, seria possível, para o autor, teorizar a respeito não só da periferia, mas do sistema capitalista como um todo (ver Cohn, 2001b; Bastos, 2002). Esse aspecto da teorização de Fernandes torna extremamente difícil o resumo e a simplificação de seus argumentos a respeito do 'capitalismo dependente'. No entanto, arriscamos a fazer aqui um pequeno esquema de seus argumentos principais.

Uma primeira dimensão de sua teorização é a necessidade de articular, na definição da dinâmica societária do 'capitalismo dependente', a conjunção estrutural de elementos 'internos' e 'externos' à sociedade de referência, por um lado, e a imbricação constitutiva entre 'antigo regime' e sociedade de classes (ou 'modernidade'), por outro. Para Fernandes, as combinações estruturais entre 'interno' e 'externo' - ou melhor, entre dependência externa 'internalizada' nas relações sociais de poder do país - e entre 'arcaísmo' e 'modernidade' seriam como duas faces da mesma moeda. Isso porque o papel de sócio menor da burguesia mundial representado pelas burguesias periféricas, ainda que permitisse a introdução de transformações profundas na estrutura social no sentido da expansão e diferenciação de uma 'ordem social competitiva', inviabilizaria a total redefinição do sistema social à luz dos princípios 'modernos':

(...) a influência externa, autenticamente revolucionária aos níveis estrutural e histórico na fase da desagregação do antigo sistema colonial, pois incorporava a economia interna diretamente ao mercado mundial e fixava os núcleos urbanos que iriam servir de fulcro ao crescimento de um mercado capitalista moderno, também pressupunha um feedback negativo. O comércio externo constituía o verdadeiro ponto de apoio seja para a manutenção seja para a ampliação de um esquema de exportação e importação que iria servir de eixo para a preservação, 
o desdobramento e a revitalização de estruturas econômicas, sociais e políticas de origem colonial (Fernandes, 1979, p. 39-40).

Trocando em miúdos, para Fernandes, o 'antigo regime', longe de constituir mero resíduo histórico, seria reposto cronicamente em virtude da dinâmica societária 'duplamente polarizada' (isto é, interna e externamente). Diante de tal quadro, talvez a principal consequência do 'capitalismo dependente' seja a baixa de voltagem que ele imprime à 'ordem social competitiva', que é incapaz de se universalizar - no vocabulário do autor, 'ordem social competitiva' é a ordem social típica do capitalismo; caso 'universalizada', a 'ordem social competitiva' estaria aberta igualmente a todos os grupos sociais (não haveria formas de estratificação extraeconômicas). Afinal, nesse contexto de um 'antigo regime' refuncionalizado pela própria sociedade de classes, o 'capitalismo dependente' estaria travejado pela "coexistência e concorrência do trabalho servil, do trabalho semilivre e livre, provocadas pela coetaneidade de várias idades históricas distintas, de modos de produção pré-capitalistas e capitalistas" (Fernandes, 1979, p. 36). Isto não significa que Fernandes não visse a formação da sociedade brasileira como um processo dinâmico, com alterações significativas ao longo do tempo - ele chega a dizer inclusive que teria havido um crescimento da 'ordem social competitiva', como expresso na "intensa absorção dos elementos em ascensão social (nacionais ou estrangeiros)" (Fernandes, 1979, p. 31). Entretanto, esse crescimento quantitativo não teria alterado a qualidade da 'ordem social competitiva': ela continuaria a "favorecer unilateralmente os grupos e classes privilegiados", que oscilariam, nas sociedades do capitalismo dependente, entre "um e cinco por cento, raramente atingindo um quarto da população total" (Fernandes, 1979, p. 31). Noutras palavras, os benefícios do desenvolvimento não atingiram todos os grupos sociais, mas seriam monopolizados pelos grupos sociais já previamente incorporados às posições estratégicas da ordem social.

Após delinear o quadro dessa deformação da 'ordem social competitiva' nos marcos do 'capitalismo dependente', Fernandes procura reter aquilo que seria mais específico a esse 'estilo' de revolução burguesa: a conexão estrutural entre desenvolvimento e autocracia - ao arrepio, portanto, das experiências 'clássicas' de passagem para o capitalismo, até então vistas como 'universais' pelo mainstream da sociologia da modernização. Esse, aliás, é o grande tema desenvolvido pelo autor na terceira parte de $A$ revolução burguesa no Brasil (1975), como podemos ver no trecho abaixo:

Aí, a Revolução Burguesa combina - nem poderia deixar de fazê-lo - transformação capitalista e dominação burguesa. Todavia, essa combinação se processa em condições econômicas e histórico-sociais específicas, que excluem qualquer probabili- 
dade de "repetição da história" ou de "desencadeamento automático" dos pré-requisitos do referido modelo democrático-burguês. Ao revés, o que se concretiza, embora com intensidade variável, é uma forte dissociação pragmática entre desenvolvimento capitalista e democracia; ou, usando-se uma notação sociológica positiva: uma forte associação racional entre desenvolvimento capitalista e autocracia (Fernandes, 2006, p. 340).

Neste artigo, exploramos rapidamente em três facetas diferentes como Luiz Costa Pinto e Florestan Fernandes, cada um a seu modo, lograram inovar consideravelmente em relação à principal teoria de seu tempo referida aos problemas da mudança social: a sociologia da modernização norte-americana. Conjugando um entendimento crítico da disciplina e das tarefas do sociólogo num contexto periférico, ambos se apoiaram na acumulação intelectual prévia propiciada por pelo menos duas décadas de pesquisa empírica e reflexão teórica - que aqui consideramos, sobretudo, através de suas investigações sobre o negro - para realizar sínteses criativas, cujo potencial de interpelação teórica, acreditamos, ainda não se esgotou.

É verdade, poderíamos objetar, que as formulações a que fizemos referência aqui, especialmente na terceira seção, foram escritas sob o grande impacto do fechamento político iniciado em 1964 e, nesse sentido, ressentem-se de uma visão muito cética e cerrada quanto às possibilidades de conexão entre desenvolvimento e democracia no Brasil. Nesse sentido, é urgente avaliar em que medida o processo de democratização inaudito que a sociedade brasileira vem experimentando nas últimas décadas tem logrado reverter ou não os impasses divisados nos textos de Costa Pinto e Fernandes que analisamos aqui - problema a que muitos autores contemporâneos têm se referido. Contudo, ainda assim, desde que pensemos em termos de processo e de sequências históricas, jamais poderemos minimizar a importância que os problemas aos quais se referiram Costa Pinto e Fernandes - como o processo excludente de desenvolvimento experimentado por longo tempo pela sociedade brasileira - têm para a atual configuração societária, seja porque acabaram dotando de novos sentidos a experiência democrática emergente, seja porque se repõem continuamente, ainda que transformados, no processo social. Afinal, não seria o agronegócio uma nova expressão de formas de 'marginalidade estrutural'? Ou será que a difícil institucionalização dos direitos de cidadania não estaria no mesmo campo de problemas de uma 'ordem social competitiva' deformada? Os exemplos poderiam ser multiplicados em várias esferas distintas.

Em suma, podemos dizer que o repertório cognitivo da sociologia do desenvolvimento dos anos 1950-1970, aqui metonimizado nos textos de Luiz Costa Pinto e Florestan Fernandes, ainda tem muito a nos interpelar, em termos teóricos, no presente. Isso não desobriga, é claro, da inevitável 
tarefa de repensar as mediações históricas, posto que a sociedade brasileira passou por transformações de monta desde a redemocratização. O que está em jogo, no fundo, é o estabelecimento de uma comunicação reflexiva entre as questões do passado e os problemas do presente, que nada mais é que uma forma de adensar o horizonte contemporâneo de teorização.

\section{Notas}

1 Bolsista Faperj de Pós-Doutorado no Programa de Pós-Graduação em História das Ciências e da Saúde (PPGHCS) na Casa de Oswaldo Cruz, Fundação Oswaldo Cruz (COC/Fiocruz), Manguinhos, Rio de Janeiro, RJ, Brasil. Doutor em Sociologia pelo Programa de Pós-Graduação em Sociologia e Antropologia (PPGSA) da Universidade Federal do Rio de Janeiro (UFRJ).<antoniobrasiljr@gmail.com>

Correspondência: Avenida Bartolomeu Mitre, 254, apartamento 902, CEP 22431-000, Leblon, Rio de Janeiro, RJ, Brasil.

2 Essa questão é subsidiária de uma problemática mais ampla que, embora informe a hipótese aqui desenvolvida, não poderá ser tratada com mais detalhes por falta de espaço. Refiro-me à questão da vida intelectual em contextos periféricos, já tratada em diversos trabalhos. Para ficarmos apenas com alguns exemplos, na literatura, por Candido (2006) e Schwarz (2000); na filosofia, por Arantes (1994); no marxismo, por Ricupero (2000); e nas artes plásticas, por Naves (1996). Para uma análise dessa questão voltada especialmente para a 'tradução' da sociologia da modernização na América Latina, ver Brasil Jr., 2011.

3 Evidentemente, o 'positivismo' sociológico sempre conviveu com críticas mais ou menos agudas às suas premissas, como podemos ver na enorme circulação internacional do livro de Charles Wright Mills, The Sociological Imagination (A imaginação sociológica), publicado em 1959. No entanto, prevalecia a ideia de que o grau de cientificidade da sociologia residia em sua 'neutralidade valorativa', nas ciências naturais como 'modelo', na 'monografia científica' como meio expressivo por excelência e no uso de 'métodos empíricos' (de preferência quantitativos) como ferramenta essencial de acesso à realidade empírica. Para uma análise detalhada de como o 'positivismo' sociológico se impôs nos Estados Unidos do pós-guerra, ver Steinmetz, 2007.

4 Esta citação foi retirada de uma conferência ditada por Costa Pinto na Universidade de Buenos Aires. No original em castelhano: “(...) no debe olvidarse de que los clásicos de nuestra disciplina, - con su pensamiento y su acción, además de fundar una ciencia -, amoldaron una sociedad; esa misma sociedad que en su apogeo descaracterizó el sentido profundamente racional y creador del pensamiento sociológico, generando, como aptitud mental predominante en cierta época, un hermetismo académico que nada tiene de auténticamente científico" (Costa Pinto, 1962, p. 7). Vale a pena lembrar que Costa Pinto não deixa de mencionar também, nesse particular, o caso do marxismo vigente na antiga União Soviética, país onde os impulsos de consolidação da ordem social também teriam afetado o caráter criador das formulações de Marx. Nas palavras do autor: "el problema de la objetividad científica de nuestra disciplina, en sus relaciones con el orden social, es mucho más 
grave y difícil en aquellas sociedades que juzgan que ya tienen hecho en el pasado su revolución estructural y donde la estabilidad es el valor dominante, que en sociedades como las nuestras (...). Obsérvese, por ejemplo, lo que pasó con el pensamiento liberal que inspiro la sociología en los Estados Unidos y en la Europa Occidental y lo que pasó con el marxismo en cuanto doctrina oficial de una súper potencia del mundo moderno y fácilmente se concluirá que el problema de la respetabilidad y de la objetividad del pensamiento científico no es exclusivamente 'latino-americano'” (Costa Pinto, 1962, p. 6).

${ }^{5}$ No original: “(...) en sociedades como las nuestras - que hoy están viviendo su revolución - en el que la variedad es un valor dominante y deseable, y que facilita la sincronización de los valores de la ciencia creadora con los valores del orden social en transformación" (Costa Pinto, 1962, p. 6).

${ }^{6}$ No original: “Llego a pensar, viendo lo que pasó con aquellas dos grandes fuentes de la sociología contemporánea, que tal vez aquí, en estos parajes, en este mundo nuevo en gestación, pueda la sociología encontrar las condiciones óptimas para germinar con el impulso de un verdadero renacimiento" (Costa Pinto, 1962, p. 6).

7 A passagem citada acima foi retirada de um livro de Costa Pinto editado na Argentina, La sociología del cambio y el cambio de la sociología. No original: “(...) quienes vivimos y trabajamos en áreas que están sufriendo un proceso rápido y reciente de transformación, podemos sentirnos colocados en una posición más ventajosa que la de los colegas que trabajan en las llamadas sociedades superdesarrolladas, donde la estabilidad, mucho más que el cambio, se presenta como valor social supremo" (Costa Pinto, 1963a, p. 142).

8 Para uma análise mais pormenorizada das pesquisas de Costa Pinto e Fernandes sobre o negro, ver Maio, 1997. Ver também, para o caso de Fernandes, Bastos, 1987 e Cohn, 2001a.

9 Costa Pinto publicou o seu relatório em forma de livro em 1953; já Fernandes retomou e estendeu consideravelmente o seu relatório inicial (feito em conjunto com Roger Bastide) em sua alentada tese de cátedra $A$ integração do negro na sociedade de classes, à qual nos referimos aqui, defendida em 1964 e publicada no ano seguinte.

10 Para uma análise das intensas relações de Florestan Fernandes com o associativismo negro de São Paulo, bem como de suas conexões de sentido, ver Silva, 2012.

$11 \mathrm{Ou}$, ainda, poderíamos recuar até o começo da década de 1940. André Botelho (2009), ao se debruçar sobre os argumentos de Costa Pinto em Lutas de famílias no Brasil, cuja primeira versão é de 1943, chamou atenção para os nexos de sentido entre a sua visão não dualista da oposição público/privado, aí presente, e a noção de 'marginalidade estrutural'.

12 Aqui, o autor realiza um diálogo explícito com algumas formulações de Charles Wright Mills (1965). 


\section{Referências}

ARANTES, Paulo E. Um departamento francês de Ultramar. São Paulo: Paz e Terra, 1994.

ARRUDA, Maria A. N. Metrópole e cultura: São Paulo no meio século XX. Bauru: Edusc, 2001.

BASTOS, Elide R. A questão racial e a revolução burguesa. In: D'INCAO, M. A. (Org.). O saber militante: ensaios sobre Florestan Fernandes. Rio de Janeiro: Paz e Terra; São Paulo: Editora Unesp, 1987. p. 79-99.

Atualidade do pensamento social brasileiro. Sociedade e Estado, Brasília, v. 26, n. 2, p. 51-70, 2011.

. Pensamento social da escola sociológica paulista. In: MICELI, Sergio (Org.). $O$ que ler na ciência social brasileira. São Paulo: Sumaré; Anpocs, 2002.

BENDIX, Reinhard. Construção nacional e cidadania. São Paulo: Edusp, 1996.

BOTELHO, André. Passagens para o Estado-nação: a tese de Costa Pinto. Lua Nova, São Paulo, n. 77, p. 147-177, 2009.

BRASIL JR., Antonio. Passagens para a teoria sociológica: Florestan Fernandes e Gino Germani. 2011. Tese (Doutorado em Ciências Humanas) - Programa de Pós-graduação em Sociologia e Antropologia, Instituto de Filosofia e Ciências Sociais, Universidade Federal do Rio de Janeiro, Rio de Janeiro, 2011.

CANDIDO, Antonio. Formação da literatura brasileira. 10 ed. Rio de Janeiro: Ouro sobre Azul, 2006.

COHN, Gabriel. A integração do negro na sociedade de classes. In: MOTA, Lourenço D. (Org.). Introdução ao Brasil: um banquete nos trópicos. 3. ed. São Paulo: Editora Senac, 2001a, v. 1. p. 385-402.

A revolução burguesa no Brasil. In: MOTA, Lourenço D. (Org.). Introdução ao
Brasil: um banquete nos trópicos. 3. ed. São Paulo: Editora Senac, 2001b, v. 2, p. 395-412.

COSTA PINTO, Luiz. La sociología del cambio y el cambio de la sociología. Buenos Aires: Eudeba, 1963a.

Jornadas Argentinas y Latinoamericanas de Sociología. Boletín de la Asociación Sociológica Argentina, Buenos Aires, n. 2, julio 1962, p. 5-9.

Modernização e desenvolvimento. In: COSTA PINTO, Luiz; BAZZANELLA, Waldomiro (Org.). Teoria do desenvolvimento. Rio de Janeiro: Zahar, 1967, p. 191-201.

O negro no Rio de Janeiro: relações de raças numa sociedade em mudança. 2. ed. Rio de Janeiro: Editora UFRJ, 1998.

Sociologia e desenvolvimento: temas e problemas de nosso tempo. Rio de Janeiro: Civilização Brasileira, 1963b.

Sociologia e mudança social. Conferência pronunciada na Sociedade Brasileira de Antropologia e Etnologia. Sociologia, São Paulo, v. 9, n. 4, 1947, p. 287-331.

COSTA PINTO, Luiz; BAZZANELLA, Waldomiro. Preâmbulo. In: (Org.). Teoria do desenvolvimento. Rio de Janeiro: Zahar, 1967, p. 9-14.

DOMINGUES, José M. Desenvolvimento, modernidade, subjetividade. In: MAIO, Mar$\cos$ C.; VILLAS BÔAS, Glaucia (Org.). Ideais de modernidade e sociologia no Brasil: ensaios sobre Luiz de Aguiar Costa Pinto. Porto Alegre: Editora UFRGS, 1999. p. 71-86.

Teoria crítica e (semi)periferia. Belo Horizonte: Editora UFMG, 2011.

FERNANDES, Florestan. A integração do negro na sociedade de classes. São Paulo: Globo, 2008a. v. 1. 
A integração do negro na sociedade de classes. São Paulo: Globo, 2008b. v. 2.

. A revolução burguesa no Brasil. São Paulo: Globo, 2006.

. A sociologia numa era de revolução social. 2. ed. Rio de Janeiro: Zahar, 1976.

Capitalismo dependente e classes sociais na América Latina. 3. ed. Rio de Janeiro: Zahar, 1981.

Mudanças sociais no Brasil. 3. ed. rev. São Paulo: Difel, 1979.

FERNANDES, Florestan; BASTIDE, Roger. Brancos e negros em São Paulo. São Paulo: Global, 2008.

FRANCO, Maria Sylvia Carvalho. O moderno e suas diferenças. 1970. Tese (Livre-Docência em Ciências Sociais) - Departamento de Ciências Sociais, Faculdade de Filosofia, Letras e Ciências Humanas, Universidade de São Paulo, São Paulo, 1970.

GILMAN, Nils. Mandarins of the Future: Modernization Theory in Cold War America. Baltimore: John Hopkins University Press, 2007.

LIEDKE FILHO, Enno D. Luiz de Aguiar Costa Pinto: a sociologia do desenvolvimento e a marginalidade estrutural. In: MAIO, Marcos C.; VILLAS BÔAS, Glaucia (Org.). Ideais de modernidade e sociologia no Brasil: ensaios sobre Luiz de Aguiar Costa Pinto. Porto Alegre: Editora UFRGS, 1999. p. 87-106.

LIMA, Nísia T. Sob o signo de Augusto Comte ou sob o signo de Karl Marx: a vocação das ciências sociais nas perspectivas de Costa Pinto e Florestan Fernandes. In: MAIO, Marcos C.; VILLAS BÔAS, Glaucia (Org.). Ideais de modernidade e sociologia no Brasil: ensaios sobre Luiz de Aguiar Costa Pinto. Porto Alegre: Editora UFRGS, 1999. p. 251-274.

LIPSET, Seymour. Political man. Nova York: Doubleday; Anchor, 1963.
MAIA, João M. E. Pensamento brasileiro e teoria social: notas para uma agenda de pesquisa. Revista Brasileira de Ciências Sociais, São Paulo, v. 24, n. 71, p. 155-168, 2009.

MAIO, Marcos C. A história do Projeto Unesco: estudos raciais e ciências sociais no Brasil. 1997. Tese (Doutorado em Ciências Políticas) - Programa de Pós-graduação em Ciência Política e Relações Internacionais, Instituto Universitário de Pesquisa do Rio de Janeiro, Rio de Janeiro, 1997.

MAIO, Marcos C; VILLAS BÔAS, Glaucia (Org.). Ideais de modernidade e sociologia no Brasil: ensaios sobre Luiz de Aguiar Costa Pinto. Porto Alegre: Editora UFRGS, 1999.

MILLS, Charles. W. Poder e politica. Rio de Janeiro: Zahar, 1965.

NAVES, Rodrigo. A forma difícil. São Paulo: Ática, 1996.

RICUPERO, Bernardo. Caio Prado Jr. e a nacionalização do marxismo. São Paulo: Editora 34, 2000.

SCHWARZ, Roberto. Ao vencedor as batatas. São Paulo: Duas Cidades; Editora 34, 2000.

SILVA, Mário A. M. Fazer história, fazer sentido: Associação Cultural do Negro (1954-1964). Lua Nova, São Paulo, n. 85, p. $227-273,2012$.

STEINMETZ, George. American Sociology before and after World War II: the (temporary) settling of a disciplinary field. In: CALHOUN, Craig. (Org.). Sociology in America: a history. Chicago: The University of Chicago Press, 2007. p. 314-366.

VILLAS BÔAS, Glaucia. Passado arcaico, futuro moderno: a contribuição de Costa Pinto à sociologia das mudanças sociais. In: MAIO, Marcos. C.; VILLAS BÔAS, Glaucia (Orgs.). Ideais de modernidade e sociologia no Brasil: ensaios sobre Luiz de Aguiar Costa Pinto. Porto Alegre: Editora UFRGS, 1999. p. 51-59. 